\title{
Effect of Temperature and Acoustic Pressure During Ultrasound Liquid-Phase Processing of Graphite in Water
}

\author{
JUSTIN A. MORTON ${ }^{10},{ }^{1,8}$ DMITRY G. ESKIN, ${ }^{2}$ NICOLE GROBERT, ${ }^{3,7}$ \\ JIAWEI MI, ${ }^{4}$ KYRIAKOS PORFYRAKIS, ${ }^{5}$ PAUL PRENTICE, ${ }^{6}$ \\ and IAKOVOS TZANAKIS ${ }^{1,3}$
}

\begin{abstract}
1.-School of Engineering, Computing and Mathematics, Oxford Brookes University, College Cl, Wheatley, Oxford OX33 1HX, UK. 2.-Brunel Centre for Advanced Solidification Technology, Brunel University London, Kingston Lane, London UB8 3PH, UK. 3.-Department of Materials, University of Oxford, Parks Rd, Oxford OX1 3PH, UK. 4.-Department of Engineering, University of Hull, Cottingham Rd, Hull HU6 7RX, UK. 5.-Faculty of Engineering and Science, Central Avenue, University of Greenwich, Chatham Maritime, Kent ME4 4TB, UK. 6.-Cavitation Laboratory, School of Engineering, University of Glasgow, University Avenue, Glasgow G128QQ, UK. 7.-Williams Advanced Engineering, Grove, Oxford OX12 0DQ, UK. 8.-e-mail: 18096707@brookes.ac.uk
\end{abstract}

\begin{abstract}
Ultrasound-assisted liquid-phase exfoliation is a promising method for manufacturing two-dimensional materials. Understanding the effect of ultrasonication parameters such as the temperature and input power on the developed pressure field is pivotal for optimization of the process. Limited research has been carried out to determine the optimal temperature for exfoliation, with some data generating disputed results. Simply maximizing the sonication power does not necessarily produce a higher yield because of shielding. In this study, a high-temperature calibrated cavitometer was used to measure the acoustic pressure generated in different graphite solutions in deionized water at various temperatures (from $10^{\circ} \mathrm{C}$ to $70^{\circ} \mathrm{C}$ ) and input power conditions (from $20 \%$ to $100 \%$ ). In addition, high-speed optical imaging provided insight on the shock wave generation from transient bubble collapses under different sonication conditions. The optimal sono-exfoliation parameters were determined to be $20 \%$ input power at $10^{\circ} \mathrm{C}$ for graphite flake solution, and $100 \%$ input power at $40^{\circ} \mathrm{C}$ to $50^{\circ} \mathrm{C}$ for graphite powder solution.
\end{abstract}

\section{INTRODUCTION}

Since the revolutionary discovery of graphene, a panoply of research into two-dimensional (2D) layered material (LM) exfoliation has been conducted. ${ }^{1}$ The wide variety of atomically structured LMs such as oxides, metal halides, clays (layered silicates), ternary transition-metal carbides, group III-VI semiconductors, and transition-metal dichalcogenides give rise to exceptional properties when exfoliated to a few or single layers. ${ }^{2,3}$ For instance, some of graphene's unique properties include record high thermal conductivity $\left(\sim 5000 \mathrm{~W} \mathrm{~m}^{-1} \mathrm{~K}^{-1}\right),{ }^{4}$ intrinsic strength of $130 \mathrm{GPa},{ }^{5}$ and a profoundly high electron mobility $\left(200,000 \mathrm{~cm}^{2} \mathrm{~V}^{-1} \mathrm{~s}^{-1}\right) .{ }^{6} \mathrm{~A}$

(Received July 9, 2021; accepted September 13, 2021; published online October 26, 2021) nonexhaustive list of applications includes optical, electronic, magnetic, photocatalytic, mechanical, and thermoelectric devices. ${ }^{7,8}$

There is also a range of top-down and/or bottomup exfoliation approaches to produce such 2D materials. Chemical vapor deposition and atomic layer deposition work by growing $2 \mathrm{D}$ sheets from gas particles onto a substrate (bottom-up), whereas mechanical exfoliation, material intercalation, and reduction of graphene oxide break and peel off bulk material layers to enact exfoliation (top-down). ${ }^{9}$ Among these approaches, liquid-phase exfoliation (LPE) via ultrasound has been proven to be particularly successful due to its ability to facilitate exfoliation of various bulk LMs in a cost-effective manner, while producing high-quality, large-surface-area $2 \mathrm{D}$ materials. ${ }^{10}$ 
Acoustic cavitation plays a pivotal role in the exfoliation process. In general, the implosion of cavitation bubbles and the associated high-pressure shock waves and high-velocity (up to several $100 \mathrm{~m} \mathrm{~s}^{-1}$ ) liquid jets ${ }^{11,12}$ generate strong shear forces that are responsible for the exfoliation. Our group recently produced clear, real-time evidence for this, demonstrating the importance of shock waves and liquid jets by using high-speed imaging and identifying the sono-exfoliation mechanisms at work. ${ }^{13}$ In particular, shock waves were shown to be the driving mechanism for exfoliation, providing sufficient force to initiate splitting of layers, which led to delamination. In addition, stable cavitation bubbles trapped within graphite layers promoted high-quality exfoliation with fewer defects in the final product by providing gentler shear forces through rapid oscillations. ${ }^{13,14}$

Despite the complementary shear forces, adverse effects deleterious to LMs such as edge defects and holes can be produced by prolonged ultrasonic treatment. ${ }^{15}$ It has also been shown that the temperature increase during sonication can result in inconsistent exfoliation. ${ }^{16}$ Hence, the implementation of a temperature control strategy is essential. Furthermore, ultrasonication at higher amplitude is not necessarily beneficial due to the shielding effect, i.e., cushioning of the acoustic emissions and shock waves from the tip of the sonotrode, ${ }^{17,18}$ which diminishes shearing of bulk material layers in solution. Our group recently showed that, by adjusting key parameters such as the ultrasonic frequency and sonotrode geometry, high-quality graphene flakes can be produced in a relatively short period of time. ${ }^{14}$

In this study, we focused on the effects of the liquid temperature and input power on the generation of cavitation to promote exfoliation based on the developed pressure field. A calibrated hightemperature cavitometer was used to measure the acoustic pressure at solution temperatures between $10^{\circ} \mathrm{C}$ and $70^{\circ} \mathrm{C}$ during the inception of exfoliation (after $\sim 5 \mathrm{~min}$ of sonication treatment). Graphite powder (GP) and graphite flakes (GF) were sonicated in deionized (DI) water, which was previously identified as an ideal medium for exfoliation due to its low cost and nontoxic nature. ${ }^{14}$ High-speed shadow-graphic imaging was also applied for different amplitudes to observe the shock wave generation alongside the acoustic pressure measurements. The results reveal that the use of specific combinations of solution temperature and acoustic power generates favorable conditions for LM exfoliation.

\section{EXPERIMENTAL PROCEDURES}

\section{Data Acquisition}

Graphite solutions were made using GF (SigmaAldrich 100 mesh, maximum $149 \mu \mathrm{m}$ ) and GP (Alfa Aesar 300 mesh, maximum $56 \mu \mathrm{m}$ ). These sources were chosen as both are commonly used for exfoliation. These two types of graphite have a different structure and size, thus the effect of cavitation development will be different for each and warrants investigation.

In a 50-mm-diameter glass beaker, $0.06 \mathrm{~g}$ graphite was mixed into $150 \mathrm{~mL}$ DI water (Hexeal Chemicals). About $\sim 60 \mathrm{~s}$ of agitation was used to disperse the GP homogeneously in the solution, whereas the GF were presonicated for $2 \mathrm{~min}$ for dispersion. Next, the solutions were set to temperatures between $10^{\circ} \mathrm{C}$ and $70^{\circ} \mathrm{C}$ using either a chiller or heating plate (ARE Heating Magnetic Stirrer, Velp Scientifica), verified using a thermocouple. When the set temperature was reached, the solution was sonicated for approximately $1 \mathrm{~min}$ to $2 \mathrm{~min}$ before a high-temperature cavitometer was introduced to capture the cavitation activity in the solution. The cavitometer consisted of a tungsten probe with a diameter of $4 \mathrm{~mm}$, having a spatial resolution of $50 \mathrm{~mm} \pm 10 \mathrm{~mm}$, calibrated at the National Physical Laboratory (UK) to frequencies between $15 \mathrm{kHz}$ and $50 \mathrm{kHz}$ (able to resolve the fundamental frequency and the corresponding suband ultraharmonics). It was submerged into the solution at an angle of $80^{\circ}$ to $80 \mathrm{~mm}$ below the water surface (Fig. 1). The corresponding readings, averaged from 60 individual readings of $2 \mathrm{~ms}$ each, were converted to spectra using fast Fourier transformation, as described previously. ${ }^{19}$ This conversion process was used to calculate the pressure values from the cavitometer output voltage. Further details and a description of the cavitometer can be found elsewhere. ${ }^{20,21}$ The data for all plots are presented as the root-mean-square (RMS) pressure for each combination of input power and temperature. These values provide an estimate for the average shearing forces that each graphite source would experience during ultrasonic treatment, as reported previously. ${ }^{13,22}$ All pressure measurements were taken with respect to ambient pressure, since the cavitometer had been calibrated at atmospheric pressure (Fig. 1).

A sonotrode (BS4d22) with a 22-mm-diameter titanium tip attached to a transducer (Hielscher UIP500hdT), with an operational frequency of 20 $\mathrm{kHz}$, was used for ultrasonic treatment. The peakto-peak amplitude of the sonotrode was between $11.4 \mu \mathrm{m}$ and $57 \mu \mathrm{m}$ (corresponding to $20 \%$ and $100 \%$ input power, respectively), with a maximum operating power at $500 \mathrm{~W}$. The sonotrode tip was lowered to $10 \mathrm{~mm}$ below the solution surface and then activated. Experiments were repeated multiple times for each combination of parameters to confirm the reproducibility of the results.

\section{High-Speed Imaging Setup}

High-speed shadow-graphic videos were captured using a Shimadzu (HPV X2) camera at a frame rate of 1 million frames per second (Fig. 2). The camera generated 256 frames for every recorded sequence, 
(a)

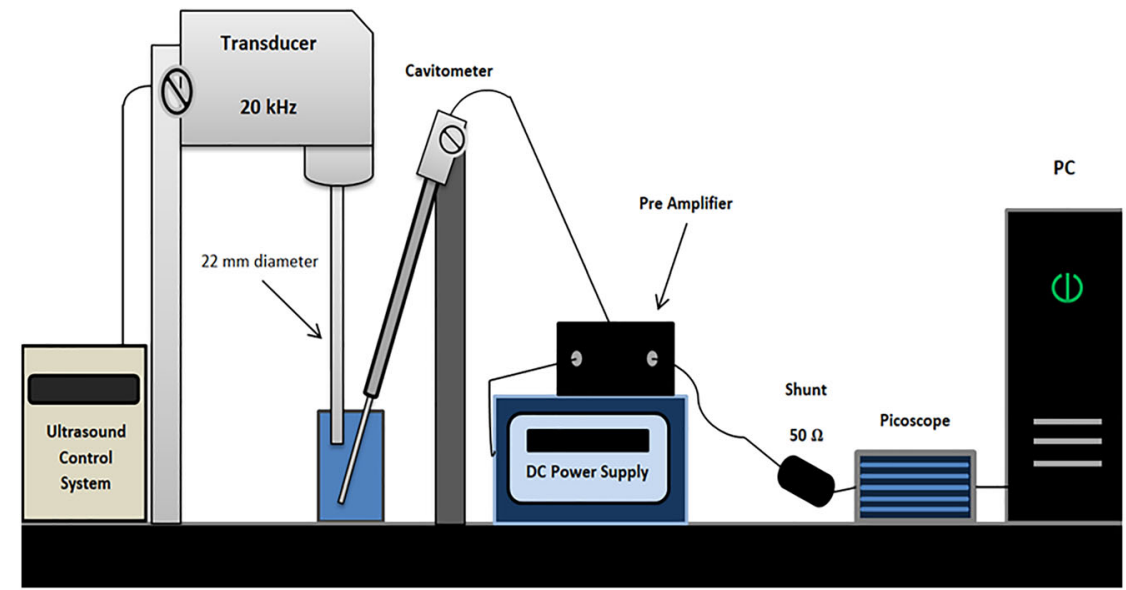

(b)

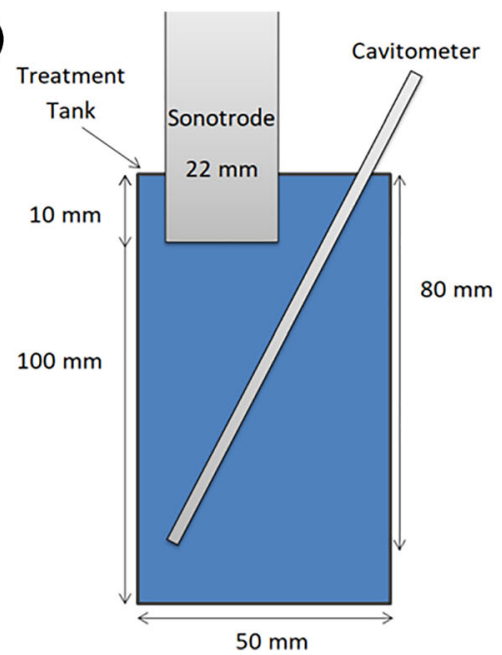

Fig. 1. Ultrasonic setup. (a) Transducer is connected to the power control unit. The cavitometer is connected to a preamplifier, power supply (Tektronix PWS2323), shunt, Picoscope, and computer for running measurement software and data acquisition. (b) Enlarged schematic of the solution dimensions of the sonotrode, cavitometer, and treatment tank.

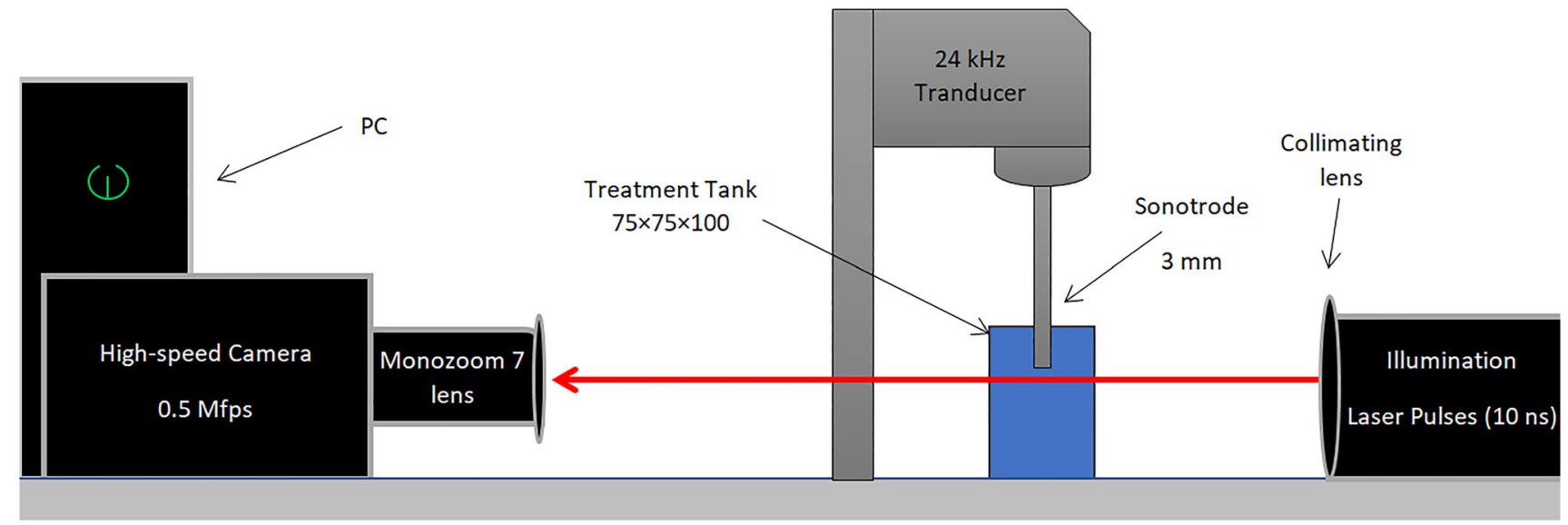

Fig. 2. Schematic showing high-speed imaging setup, whereby the laser illumination passes through the treatment tank, where images are resolved by the camera and processed on the PC

producing shadow-graphic images with a resolution of $400 \times 250$ pixels. Unlike visible-light illumination, the use of a laser enables the observation of propagating shock waves from transient cavitation collapses. Synchronized 10-ns laser pulses through a collimating lens provided the illumination (CAVILUX Smart UHS system) and effective temporal resolution to observe the generated shock waves.

To produce high-quality images using our camera and lens setup that would also show the entire sonotrode tip, a Hielscher UP200S with a 3-mmdiameter titanium sonotrode and an operational frequency of $24 \mathrm{kHz}$ was used to observe cavitation and shock wave generation. The peak-to-peak amplitude was set to $42 \mu \mathrm{m}$ and $210 \mu \mathrm{m}$, corresponding to operating power of $40 \mathrm{~W}$ and $200 \mathrm{~W}$ (20 and $100 \%$ ), respectively.

\section{RESULTS AND DISCUSSION}

\section{Temperature Effect on Acoustic Pressure}

Figure $3 \mathrm{a}$ shows that the highest acoustic pressure (up to $250 \mathrm{kPa}$ ) was produced at $20 \%$ input power in the GF solution at $10^{\circ} \mathrm{C}$. Solutions for GP and DI water also gave rise to the highest pressure readings at $10^{\circ} \mathrm{C}$, due to their respective trends. Furthermore, the acoustic pressure for the GF solution and DI water gradually decreased with increasing temperature, while for the GP solution there was a slight increase in pressure above $40^{\circ} \mathrm{C}$.

At $50 \%$ power (Fig. $3 \mathrm{~b}$ ), all the studied solutions produced the highest acoustic pressures at $10^{\circ} \mathrm{C}$. Thereafter, the acoustic pressure decreased with increasing temperature and remained approximately level from $30^{\circ} \mathrm{C}$ onwards for the $\mathrm{GF}$ and $10^{\circ} \mathrm{C}$ onwards for the GP. The DI water solution 

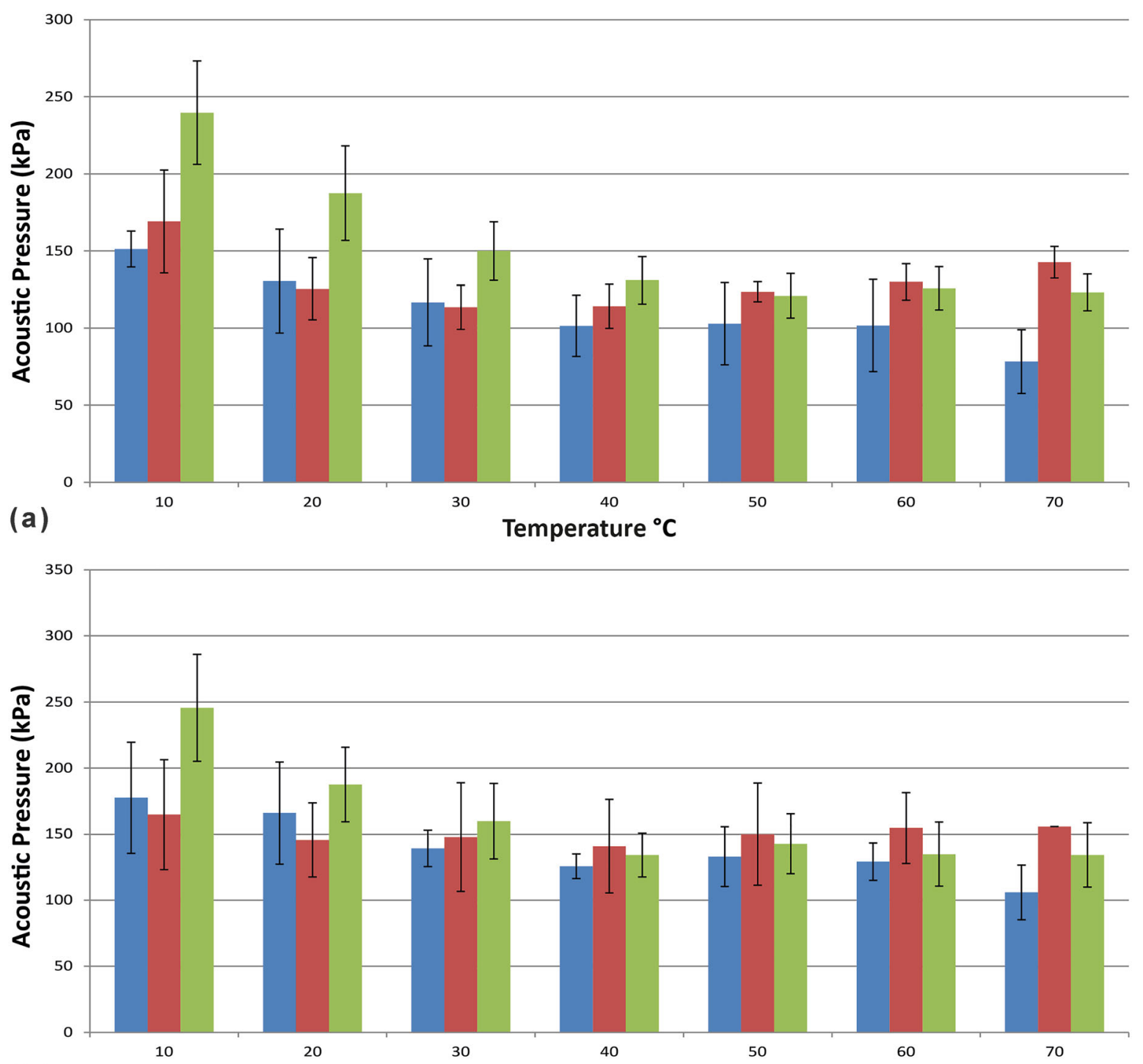

(b)

Temperature ${ }^{\circ} \mathrm{C}$

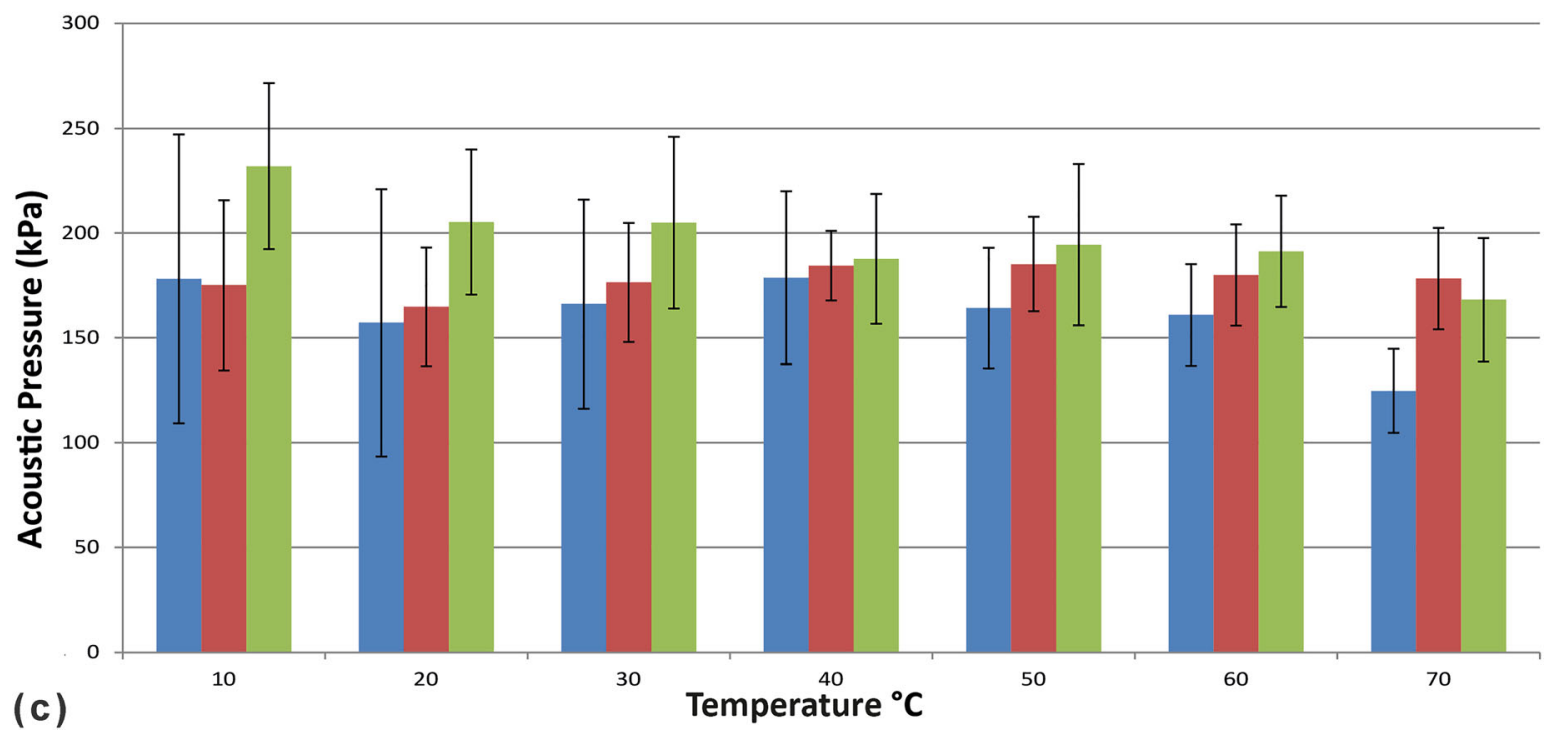

Fig. 3. Comparison of the RMS acoustic pressure (averaged over $120 \mathrm{~ms}$ ) for three solution types: DI water (blue), GP (red), and GF (green) at (a) $20 \%$, (b) $50 \%$, and (c) $100 \%$ input power (Color figure online) 


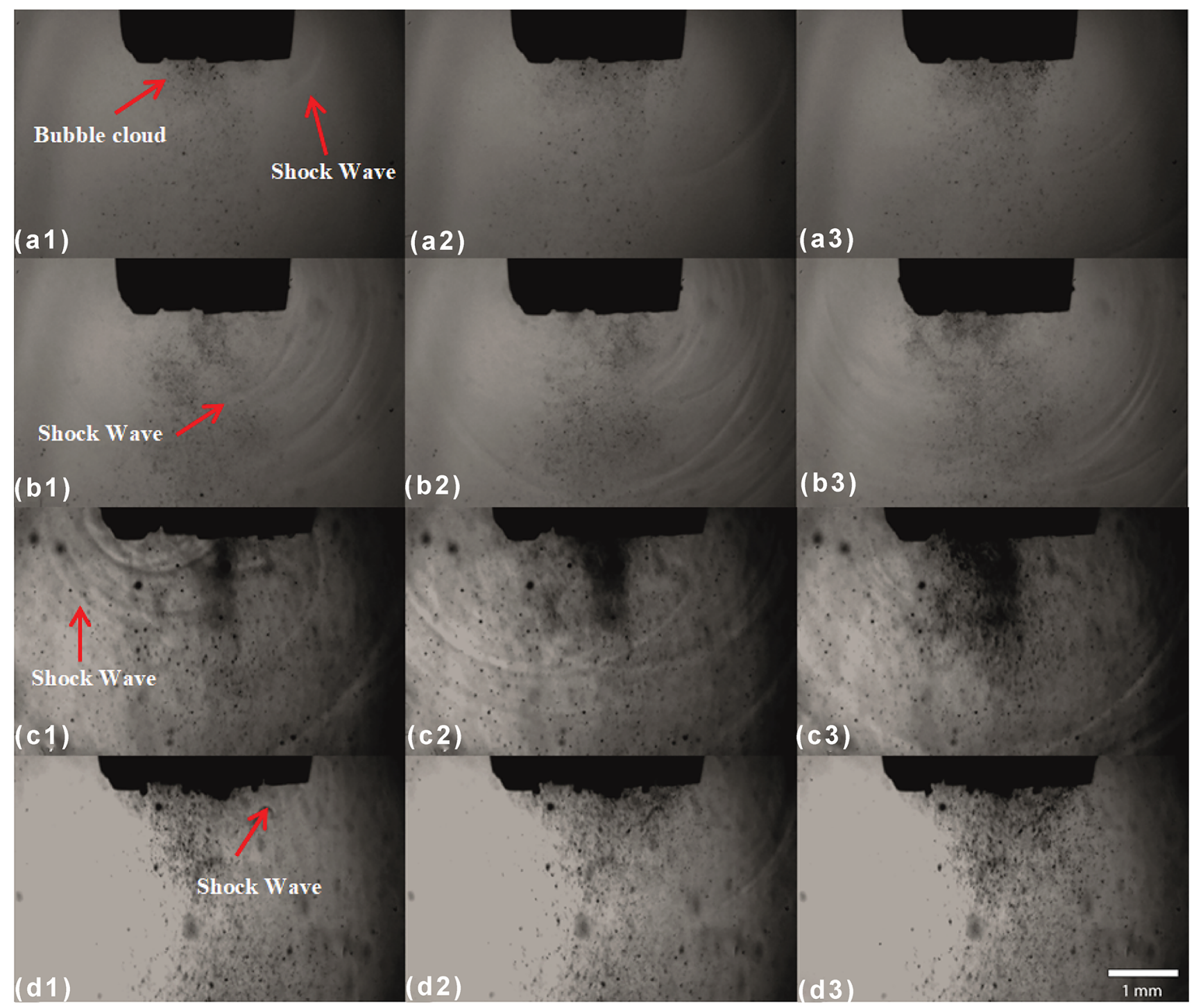

Fig. 4. Representative shadow-graphic images showing shock wave generation for input power of (a) $20 \%$ and (b) $100 \%$ at $20^{\circ} \mathrm{C}$, and shock wave generation at (c) $10^{\circ} \mathrm{C}$ and (d) $70^{\circ} \mathrm{C}$ at $100 \%$ input power in DI water. Each image is $1 \mu \mathrm{s}$ from the preceding one

showed a slight downwards trend with temperature.

The GF solution at $100 \%$ input power (Fig. 3c) showed a downward trend from $10^{\circ} \mathrm{C}$ onwards, though not as pronounced as at lower powers. On the other hand, the GP trend showed less regularity, with the largest pressures being registered at $40^{\circ} \mathrm{C}$ to $60^{\circ} \mathrm{C}$. Interestingly, the pressures for the GP solution lay in the range of $165 \mathrm{kPa}$ to $185 \mathrm{kPa}$, while those for the GF solution varied over a much larger range of $170 \mathrm{kPa}$ to $270 \mathrm{kPa}$, but this pressure difference was smaller than that of GF solution at $50 \%$ and $20 \%$ input power (135 $\mathrm{MPa}$ to $245 \mathrm{MPa}$ and $125 \mathrm{MPa}$ to $240 \mathrm{MPa}$, respectively). The decrease in the variation of the acoustic pressure in such a small volume as a consequence of the increased input power is likely due to the shielding phenomenon. ${ }^{18}$ Lower input powers produced less shielding, meaning the propagation of acoustic waves tended to be undisrupted (discussed in Fig. 4).

The general decrease of the acoustic pressure with temperature is likely due to the increase of the number of bubbles and vapor pressure (Laplace pressure) inside those bubbles, hence making them less likely to collapse. In addition, higher water temperature increased the tendency for bubble formation from gas nuclei, meaning the pressure inside the bubble was higher than the vapor pressure at that corresponding temperature, making transient cavitation collapse less likely. Furthermore, higher solution temperatures reduced the bubble surface tension, also decreasing the number of bubble implosions.

At low temperatures such as $10^{\circ} \mathrm{C}$, vapor cavitation bubbles had a greater tendency to nucleate as opposed to gas cavitation bubbles (although lower in numbers overall), and were usually more energetic, 
exhibiting more violent collapses. These generally featured shorter life-cycles (one or two acoustic cycles) before catastrophic implosion, generating higher-pressure emissions. ${ }^{23,24}$ Thus, a trade-off between the formation of vapor and gas bubbles with temperature rise regulated the pressure field in the solution.

DI water solutions generally produced lower pressures, whereas addition of GF or GP mostly increased the measured acoustic intensity. This is likely due to the addition of graphite particulates, which created more nucleation sites; in particular for the GF with a larger surface area compared with the much smaller GP particles. This observation also applies for the temperature change. We see that the GF gave rise to a much larger range of pressures with temperature, as opposed to the GP source, where the small surface area was affected less by the variation of the number of nucleating bubbles with higher temperatures.

Although most of the acoustic pressure values for $100 \%$ input power were larger than those at lower input powers, a few selected parameters did demonstrate greater shearing pressures. For GP solutions, the best candidates were $40^{\circ} \mathrm{C}$ and $50^{\circ} \mathrm{C}$ at $100 \%$ input power, both giving rise to $185 \mathrm{kPa}$, in accordance with previously reported high yields at $40^{\circ} \mathrm{C}^{14,25,26}$ as well as with previous research, where under similar conditions it was shown numerically that the largest pressure corresponded to $35^{\circ} \mathrm{C} .^{23}$ However, using $10^{\circ} \mathrm{C}$ at $20 \%$ input power and $10^{\circ} \mathrm{C}$ at $50 \%$ input power gave rise to $169 \mathrm{kPa}$ and 165 $\mathrm{kPa}$, respectively. Therefore, from $20 \%$ to $100 \%$ input power, we saw only a $9.5 \%$ increase in acoustic pressure (at the cost of five times more power).

However, for a solution to be kept at $10^{\circ} \mathrm{C}$ throughout a prolonged sonication period, more energy would be needed due to the release of acoustic energy, raising the solution temperature, whereas maintaining a temperature of around $40^{\circ} \mathrm{C}$ to $50^{\circ} \mathrm{C}$ should require less temperature control as a thermal balance in the solution may be reached naturally.

We also hypothesize that, since the shock waves are the governing mechanism of the exfoliation process, ${ }^{13}$ the stronger the pressure field, the more efficient the exfoliation should be. However, using $100 \%$ power (even in the presence of strong cavitation shielding) may cause excessive damage to the produced flakes, thus lowering their quality as well as decreasing the surface area due to more inertial bubble implosions. On the other hand, the low power of $20 \%$ generates a pressure regime that is slightly (by $16 \mathrm{kPa}$ ) lower than that seen at $100 \%$. However, the extended cavitation zone is suppressed. ${ }^{24}$ We have previously seen that the extent of the cavitation zone is important ${ }^{22}$ as it regulates the efficiency of the exfoliation. ${ }^{13}$ Graphite particles closer to the tip of the sonotrode (where the majority of the shock waves are generated) exfoliate at a faster rate. Additionally, the flows induced by acoustic streaming at lower input power, i.e., $20 \%$, are not powerful enough to generate a recirculating pattern that will continuously feed the cavitation zone with untreated graphite particles. This can be even more of an issue in the case of GF due to their large size and shape. It was previously shown that, by doubling the power amplitude, the acoustic streaming and corresponding vortices may increase their velocity by five times, promoting a higher throughput of graphite particles from the energetic zone close to the sonotrode tip. ${ }^{20}$

It can thus be deduced that an input power between these two extremes (20\% and 100\%) such as $50 \%$ could be ideal as it would offer a larger cavitation zone while avoiding damaging the exfoliated nanosheets. Therefore, a power setting of 50\% at $40^{\circ} \mathrm{C}$ to $50^{\circ} \mathrm{C}$ could also be a promising candidate for promoting exfoliation, using the powder source. For GF solutions, the highest pressures (approximately $240 \mathrm{kPa}$ ) were generated at $10^{\circ} \mathrm{C}$ using all input powers. As the highest power setting generated slightly lower acoustic pressure, at the cost of five times more energy, one can conclude that $20 \%$ power at $10^{\circ} \mathrm{C}$ would be an ideal parameter set for the GF source. However, the issue of temperature control and the smaller cavitation zone, reducing the effective treatment area, would pose the same issue. An optimal combination may emerge by considering these results together. To experimentally verify the pressure measurements, the next section presents high-speed shadow-graphic imaging.

\section{Input Power Effect on Shock Wave Generation}

When observing the production of cavitation clouds under a sonotrode, we can see how using larger input powers creates a larger cavitation zone, with more acoustic emissions. However, as discussed in regard to Fig. 3, although larger input powers create more cavitation, this does not necessarily lead to higher acoustic pressures. Figure 4 shows shadow-graphic images taken under the tip of a sonotrode.

Figure 4a1 shows the initial release of shock waves under the sonotrode tip at $20 \%$ power. In Fig. $4 \mathrm{a} 2$, a3, these can be seen propagating away from the tip. Figure $4 \mathrm{~b}$ shows the same phenomenon at $100 \%$ power, where each image in the sequence shows the propagation of the shock wave $1 \mu$ s later. The obvious difference between the two input powers is the number of shock wave bands generated. By counting and comparing the number of released shock waves in the image sequences taken at $20 \%$ and $100 \%$ power, we calculated $\sim 33 \%$ more shock waves for the $100 \%$ power setting. This analysis was done for numerous images to obtain representative qualitative statistics. For the various measured acoustic pressures from Fig. 3 to be similar despite the larger input power (which has 
Table I. Summary of sonication parameters and their effect on cavitation generation and behavior

\begin{tabular}{|c|c|}
\hline $\begin{array}{l}\text { Sonication } \\
\text { parameter }\end{array}$ & Effect on cavitation \\
\hline Low input power & $\begin{array}{l}\text { Less shock waves } \\
\text { Less shielding } \\
\text { Smaller cavitation zone }\end{array}$ \\
\hline High input power & $\begin{array}{l}\text { More shock waves } \\
\text { More shielding } \\
\text { Larger cavitation zone }\end{array}$ \\
\hline Low temperature & $\begin{array}{l}\text { More transient/vapor bubbles } \\
\text { More shock waves }\end{array}$ \\
\hline High temperature & $\begin{array}{l}\text { More gas bubbles (less prone } \\
\text { to collapse) } \\
\text { Less shock waves }\end{array}$ \\
\hline
\end{tabular}

just been demonstrated to produce more shock waves), we can deduce that these emissions were obstructed by the additional cluster of bubbles due to the higher input power. Therefore, following the discussion in Sect. 3.1, one could aim to choose an input power that produces the maximum number of shock waves while also limiting the size of the cavitation cloud such that the propagating shock waves are not impeded or cushioned by the additional nucleated cavitating bubbles (i.e., shielding).

Figure $4 \mathrm{c}$ and $\mathrm{d}$ show the release of shock waves for $10^{\circ} \mathrm{C}$ and $70^{\circ} \mathrm{C}$ solutions in DI water, respectively. These selected images were chosen to highlight representative shock wave generation during the recorded clips. At $10^{\circ} \mathrm{C}$ (Fig. 4c), we see many more, and clearer bands of shock waves propagating from the sonotrode tip, whereas at $70^{\circ} \mathrm{C}$ (Fig. $4 \mathrm{~d}$ ), the number of shock waves is reduced (indicating a reduction of transient cavitation collapses, as discussed in Sect. 3.1). This may explain why acoustic pressure measurements for $10^{\circ} \mathrm{C}$ are often greater than those in the higher temperature range $\left(70^{\circ} \mathrm{C}\right)$.

Table I summarizes the findings of this paper, where the consequential effects of the sonication parameters are listed. Taking these parameters into account, in conjunction with the discussion on beneficial input power and solution temperature, a trade-off that is beneficial for graphite exfoliation should be found. Future research will focus on the combination of prolonged period experiments followed by characterization of the resulting samples.

\section{CONCLUSION}

Based on the measured acoustic pressure field, $20 \%$ power at $10^{\circ} \mathrm{C}$ was the optimal parameter setting for the GF solution in terms of the magnitude of the pressure. For the GP source, 20\% power at $10^{\circ} \mathrm{C}$ also produced the highest pressure. This combination of low power and low temperature generated high acoustic pressures and was beneficial because less bubbly clouds formed that may have suppressed the effect from multiple bubble collapses. However, for a more practical exfoliation method, the use of $50 \%$ input power at $40^{\circ} \mathrm{C}$ may provide a more appropriate treatment area and flow conditions, while minimizing damage to the exfoliated nanosheets and reducing energy input. These findings were further validated with high-speed images, confirming that using the highest input powers was often inefficient, and that despite the increased generation of shock waves, the effect on potential shearing pressures for graphite could be lesser.

Taking this research to the next step will include in situ measurements of acoustic pressures over long sonication periods (up to $2 \mathrm{~h}$ ) to serve as a tool able to identify notable changes in acoustic pressure or spectra that will indicate the formation of graphene, verified via characterization of the produced samples.

\section{ACKNOWLEDGEMENTS}

This work has been funded by the UK Engineering and Physical Sciences Research Council (EPSRC) to the project "Sustainable and industrially scalable ultrasonic liquid phase exfoliation technologies for manufacturing 2D advanced functional materials" (EcoUltra2D), with grant nos. EP/ R031665/1; EP/R031401/1; EP/R031819/1; EP/ R031975/1.

\section{CONFLICT OF INTEREST}

For this research the authors declare that they have no conflicts of interest.

\section{OPEN ACCESS}

This article is licensed under a Creative Commons Attribution 4.0 International License, which permits use, sharing, adaptation, distribution and reproduction in any medium or format, as long as you give appropriate credit to the original author(s) and the source, provide a link to the Creative Commons licence, and indicate if changes were made. The images or other third party material in this article are included in the article's Creative Commons licence, unless indicated otherwise in a credit line to the material. If material is not included in the article's Creative Commons licence and your intended use is not permitted by statutory regulation or exceeds the permitted use, you will need to obtain permission directly from the copyright holder. To view a copy of this licence, visit $h$ ttp://creativecommons.org/licenses/by/4.0/.

\section{REFERENCES}

1. K.S. Novoselov, A.K. Geim, S.V. Morozov, D. Jiang, Y. Zhang, S.V. Dubonos, I.V. Grigorieva, and A.A. Firsov, Science 306, 666. (2004).

2. V. Nicolosi, M. Chhowalla, M. G. Kanatzidis, M. S. Strano, J. N. Coleman, Science 340, 6149. (2013).

3. A.K. Geim, Science 324, 1530. (2009). 
4. A.A. Balandin, S. Ghosh, W. Bao, I. Calizo, D. Teweldebrhan, F. Miao, and C.N. Lau, Nano Lett. 8, 902. (2008).

5. C. Lee, X. Wei, J.W. Kysar, and J. Hone, Science 321, 385. (2008).

6. K.I. Bolotin, K.J. Sikes, Z. Jiang, M. Klima, G. Fudenberg, J. Hone, P. Kim, and H.L. Stormer, Solid State Commun. 146, 351. (2008).

7. Q.H. Wang, K. Kalantar-Zadeh, A. Kis, J.N. Coleman, and M.S. Strano, Nat. Nanotechnol. 7, 699. (2012).

8. J.A. Wilson, and A.D. Yoffe, Adv. Phys. 18, 193. (1969).

9. Y. Xu, H. Cao, Y. Xue, B. Li, and W. Cai, Nanomaterials 8, 942. (2018).

10. A. Amiri, M. Naraghi, G. Ahmadi, M. Soleymaniha, and M. Shanbedi, FlatChem 8, 40. (2018).

11. N.K. Bourne, and J.E. Field, J. Fluid Mech. 244, 225. (1992),

12. I. Tzanakis, D.G. Eskin, A. Georgoulas, and D.K. Fytanidis, Ultrason. Sonochem. 21, 866. (2014).

13. J.A. Morton, M. Khavari, L. Qin, B.M. Maciejewska, A.V. Tyurnina, N. Grobert, D.G. Eskin, J. Mi, K. Porfyrakis, P. Prentice, and I. Tzanakis, Mater. Today. (2021).

14. A.V. Tyurnina, I. Tzanakis, J. Morton, J. Mi, K. Porfyrakis, B.M. Maciejewska, N. Grobert, and D.G. Eskin, Carbon N. Y. 168, 737. (2020).

15. J. Shen, Y. He, J. Wu, C. Gao, K. Keyshar, X. Zhang, Y. Yang, M. Ye, R. Vajtai, J. Lou, and P.M. Ajayan, Nano Lett. 15, 5449. (2015).

16. P. Turner, M. Hodnett, R. Dorey, and J.D. Carey, Sci. Rep. 9, 1. (2019)
17. I. Tzanakis, G.S.B. Lebon, D.G. Eskin, and K.A. Pericleous, J. Mater. Process. Technol. 229, 582. (2016).

18. B.A. Moussatov, and C. Granger, Ultrason. Sonochem. 10, 191. (2003).

19. G.S.B. Lebon, I. Tzanakis, K. Pericleous, and D.G. Eskin, Ultrason. Sonochem. 42, 411. (2018).

20. G.S.B. Lebon, I. Tzanakis, K. Pericleous, D.G. Eskin, and P.S. Grant, Ultrason. Sonochem. 55, 243. (2019).

21. M. Khavari, A. Priyadarshi, T. Subroto, C. Beckwith, K. Pericleous, D.G. Eskin, I. Tzanakis, Ultrason. Sonochem. 76, 915. (2021).

22. A. Priyadarshi, M. Khavari, T. Subroto, M. Conte, P. Prentice, K. Pericleous, D. Eskin, J. Durodola, and I. Tzanakis, Ultrason. Sonochem. 70, 105260. (2020).

23. K. Peng, F.G.F. Qin, R. Jiang, and S. Kang, Ultrason. Sonochem. 69, 105253. (2020).

24. I. Tzanakis, G.S.B. Lebon, D.G. Eskin, and K.A. Pericleous, Ultrason. Sonochem. 34, 651. (2017).

25. J. Kim, S. Kwon, D.H. Cho, B. Kang, H. Kwon, Y. Kim, S.O. Park, G.Y. Jung, E. Shin, W.G. Kim, H. Lee, G.H. Ryu, M. Choi, T.H. Kim, J. Oh, S. Park, S.K. Kwak, S.W. Yoon, D. Byun, Z. Lee, C. Lee, Nat. Commun. 6, 1-9. (2015).

26. M.J. Peng He, C. Zhou, S. Tian, J. Sun, S. Yang, G. Ding, and X. Xie, Chem. Commun. 51, 4651. (2015).

Publisher's Note Springer Nature remains neutral with regard to jurisdictional claims in published maps and institutional affiliations. 